\title{
Gambaran tingkat inteligensi mahasiswa tahun pertama program studi pendidikan dokter fakultas kedokteran universitas sam ratulangi
}

\author{
${ }^{1}$ Nadine L.H.S. Montolalu \\ ${ }^{2}$ Hendri Opod \\ ${ }^{2}$ Cicilia Pali
}

\author{
${ }^{1}$ Kandidat Skripsi Fakultas Kedokteran Universitas Sam Ratulangi Manado \\ ${ }^{2}$ Bagian Psikologi Fakultas Kedokteran Universitas Sam Ratulangi Manado \\ Email: nadinmontolalu@gmail.com
}

\begin{abstract}
Intelligence is one of the mental, mind, and human intellectual ability. Problem Based Learning (PBL) learning system used in medical faculty requires students to be able to correlate the various sciences, concepts and theories to solve health problems. Good intelligence capability was considered as one of the important things. This thesis aims was to describe the intelligence level of the first-year physician education courses students. The research was a descriptive research with cross sectional study approach. Respondents in this research were 101 people who fulfilled the inclusion criteria. Intelligence test's tool used was Intelligenz Struktur Test (IST). The results of this research was obtained IQ level, 1 subject (1\%) in very superior category, 15 subjects $(15 \%)$ in superior category, 28 subjects $(28 \%)$ in high-average category, 49 subjects $(48 \%)$ in average category, 7 subjects $(7 \%)$ in low-average category, and 1 subject (1\%) in weak boundary category. Conclusion: Based on the results, can be concluded that intelligence level in most (48\%) of the first-year physician education courses students at medical faculty of Sam Ratulangi University was in average category.
\end{abstract}

Keywords: IQ, intelligence level, medical student

\begin{abstract}
Abstrak: Inteligensi adalah salah satu kemampuan mental, pikiran atau intelektual manusia. Sistem pembelajaran Problem Based Learning (PBL) yang digunakan di fakultas kedokteran menuntut mahasiswa agar mampu mengorelasikan berbagai ilmu, konsep dan teori untuk menyelesaikan masalah-masalah kesehatan. Kemampuan inteligensi yang baik dipertimbangkan sebagai salah satu hal penting. Tujuan dari penelitian ini adalah untuk mengetahui gambaran tingkat inteligensi mahasiswa tahun pertama program studi pendidikan dokter. Penelitian yang digunakan bersifat deskriptif dengan pendekatan studi potong lintang. Responden dalam penelitian ini berjumlah 101 orang yang memenuhi kriteria inklusi. Alat tes inteligensi yang digunakan adalah Intelligenz Struktur Test (IST). Hasil yang didapatkan, tingkat kemampuan IQ dengan kategori sangat superior 1 subyek (1\%), kategori superior 15 subyek (15\%), kategori rata-rata tinggi 28 subyek (28\%), kategori rata-rata 49 subyek (48\%), kategori dibawah rata-rata 7 subyek (7\%), dan sisanya 1 subyek (1\%) pada kategori batas lemah. Simpulan: Berdasarkan hasil penelitian, dapat disimpulkan bahwa tingkat inteligensi mahasiswa program studi pendidikan dokter Fakultas Kedokteran Universitas Sam Ratulangi terbanyak (48\%) berada pada kategori rata-rata.
\end{abstract}

Kata kunci: IQ, tingkat inteligensi, mahasiswa kedokteran.

Salah satu cita-cita bangsa Indonesia yang tercantum dalam Pembukaan UndangUndang Dasar adalah mencerdaskan kehidupan bangsa. Sejalan dengan cita-cita bangsa Indonesia tersebut, maka pendidikan merupakan hal yang 
diprioritaskan salah satunya pendidikan tinggi. ${ }^{1}$ Pendidikan tinggi di Indonesia diatur dalam Undang-Undang No 12 tahun 2012. Di dalamnya mengatakan bahwa pengembangan Ilmu Pengetahuan dan Teknologi dilakukan oleh sivitas akademika melalui pembelajaran dan/atau penelitian ilmiah. Sivitas akademika yang dimaksud salah satunya adalah mahasiswa. Mahasiswa harus secara aktif mengembangkan potensinya dengan melakukan pembelajaran. ${ }^{2}$

Dalam membangun aktivitas belajar yang berkualitas dan efektif maka pemahaman tentang potensi-potensi setiap individu sangat diperlukan. Potensi-potensi yang tidak dikelola dengan benar karena ketidaktahuan atau ketidakpedulian dapat menjadi hambatan dalam belajar dan pembelajaran. Salah satu potensi yang dimiliki pelajar-mahasiswa adalah inteligensi. ${ }^{3}$

Inteligensi adalah salah satu kemampuan mental, pikiran atau intelektual manusia. Inteligensi memampukan individu untuk menyelesaikan masalah-masalah yang disesuaikan dengan kebutuhan hidup. ${ }^{4}$ Dari berbagai definisi mengenai inteligensi yang ada, Solso, Maclin O, dan Maclin $\mathrm{M}^{5}$ menyimpulkan bahwa inteligensi manusia adalah kemampuan untuk memperoleh, memanggil kembali (recall), dan menggunakan pengetahuan untuk memahami konsep-konsep abstrak maupun konkret dan hubungan antara objek dan ide, serta menerapkan pengetahuan secara tepat. Inteligensi seseorang biasanya dinyatakan dalam suatu angka inteligensi yaitu Intelligence Quotient (IQ). ${ }^{3}$

IQ seseorang dapat dinilai melalui tes inteligensi. Tes inteligensi adalah alat yang sudah distandarisasi dan obyek untuk menilai kemampuan intelektual. Khairani dalam bukunya mengemukakan bahwa di dalam tes inteligensi dapat diungkapkan tentang pengertian, kemampuan dalam bidang pengetahuan umum, kecepatan berfikir dan bekerja, ingatan, perbendaharaan bahasa, ketelitian asosiasi dan konsentrasi seseorang. ${ }^{3}$ Sistem pembelajaran Problem Based Learning
(PBL) yang digunakan di fakultas kedokteran menuntut mahasiswa agar mampu mengorelasikan berbagai ilmu, konsep dan teori untuk menyelesaikan masalah-masalah kesehatan. Kemampuan inteligensi yang baik dipertimbangkan sebagai salah satu hal penting, karena diyakini dapat berpengaruh terhadap kemampuan berpikir logis, kemampuan menganalisis, dan kemampuan untuk memecahkan masalah dalam pekerjaannya $^{9,10}$.

Beragam individu yang masuk di Fakultas Kedokteran Universitas Sam Ratulangi memiliki potensi yang berbedabeda. Potensi yang ada menurut peneliti perlu diidentifikasi, salah satunya potensi dalam hal kemampuan inteligensi mahasiswa yang dapat diketahui dengan melakukan tes inteligensi, agar ketidaktahuan mengenai potensi mahasiswa dalam hal ini inteligensi yang nantinya dapat menjadi hambatan dalam pembelajaran mahasiswa dapat dihindari. ${ }^{3}$ Atas dasar itulah peneliti tertarik melakukan penelitian untuk mengetahui gambaran tingkat inteligensi mahasiswa tahun pertama program studi pendidikan dokter Fakultas Kedokteran Universitas Sam Ratulangi.

\section{METODE PENELITIAN}

Penelitian ini bersifat deskriptif dengan pendekatan cross sectional. Penelitian ini dilaksanakan pada bulan November 2016 di Fakultas Kedokteran Universitas Sam Ratulangi di Kleak, Manado. Responden dalam penelitian ini berjumlah 101 orang yang sesuai kriteria inklusi yaitu Mahasiswa Program Studi Pendidikan Dokter Fakultas Kedokteran UNSRAT Angkatan 2016 yang hadir saat pengambilan data serta bersedia menjadi responden penelitian setelah responden mengisi lembar informed consent.

Alat tes yang digunakan untuk mengukur nilai IQ responden dalam penelitian ini adalah Intelligenz Struktur Test (IST) oleh Amthaeur. Kemudian hasil tes IQ diolah untuk mendapatkan nilai IQ menggunakan aplikasi IST. Nilai IQ yang 
didapatkan kemudian diolah menggunakan Microsoft Office Excel 2007.

\section{HASIL PENELITIAN}

Subyek penelitian adalah mahasiswa program studi pendidikan dokter fakultas kedokteran Universitas Sam Ratulangi Manado yang berjumlah 101 orang, yang terbagi atas 37 subyek (37\%) laki-laki dan 64 subyek $(63 \%)$ perempuan. Subyek penelitian terbanyak pada usia 18 tahun, yaitu sebanyak 46 subyek $(46 \%)$, diikuti usia 17 tahun sebanyak 37 subyek (37\%). Sedangkan jumlah subyek yang paling sedikit terdapat pada usia 20 tahun, yaitu sebanyak 2 subyek (2\%).

Nilai IQ didapatkan melalui proses tes IQ menggunakan alat tes IST. Distribusi nilai dapat dilihat pada tabel 2.6. Rata-rata nilai IQ diperoleh 108,63 dengan nilai yang paling sering muncul yaitu 109. Nilai terkecil adalah 77 dan nilai terbesar adalah 151.
Berdasarkan Tabel 1 didapatkan sebagian besar subyek masuk dalam kategori rata-rata yaitu sebanyak 49 subyek (49\%) dengan rata-rata nilai IQ

102,29. Subyek paling sedikit terdapat pada kategori sangat superior dan batas lemah masing-masing terdiri atas 1 subyek.

Berdasarkan Tabel 2 terlihat pada kategori sangat superior dengan nilai IQ $\geq 140$ didapatkan pada subyek perempuan sebanyak 1 subyek (2\%). Dari total 37 subyek laki-laki dan 64 subyek perempuan, didapatkan subyek terbanyak berada di kategori rata-rata dengan nilai IQ 90-109 yaitu masing-masing sebanyak 18 subyek (49\%) laki-laki dan 42 subyek (66\%) perempuan. Persentasi subyek laki-laki lebih besar dibanding persentasi subyek perempuan pada kategori rata-rata tinggi sampai sangat superior. Sedangkan pada ketegori rata-rata sampai batas lemah persentasi subyek laki-laki lebih kecil dibanding persentasi subyek perempuan.

Tabel 1. Distribusi nilai IQ berdasarkan kategori nilai

\begin{tabular}{|c|c|c|c|c|}
\hline Kategori & Nilai IQ & Frekuensi & Persentase & Rerata Nilai IQ \\
\hline Sangat superior & $\geq 140$ & 1 & $1 \%$ & 151,00 \\
\hline Superior & $120-139$ & 15 & $15 \%$ & 124,53 \\
\hline Rata-rata tinggi & $110-119$ & 28 & $28 \%$ & 113,89 \\
\hline Rata-rata & $90-109$ & 49 & $48 \%$ & 102,29 \\
\hline Rata-rata rendah & $80-89$ & 7 & $7 \%$ & 87,29 \\
\hline Batas lemah & $70-79$ & 1 & $1 \%$ & 77,00 \\
\hline Lemah mental & $30-69$ & 0 & $0 \%$ & - \\
\hline Total & & 101 & $100 \%$ & 108,63 \\
\hline
\end{tabular}

Tabel 2. Gambaran Tingkat IQ Berdasarkan Jenis Kelamin

\begin{tabular}{lcrrrc}
\hline \multicolumn{1}{c}{ Kategori } & \multirow{2}{*}{ IQ } & \multicolumn{2}{c}{ Laki-laki } & \multicolumn{2}{c}{ Perempuan } \\
& & $\mathrm{N}$ & $\%$ & $\mathrm{~N}$ & $\%$ \\
\hline Sangat Superior & $\geq 140$ & 0 & $0 \%$ & 1 & $2 \%$ \\
Superior & $120-139$ & 10 & $27 \%$ & 5 & $8 \%$ \\
Rata-rata Tinggi & $110-119$ & 7 & $19 \%$ & 10 & $16 \%$ \\
Rata-rata & $90-109$ & 18 & $49 \%$ & 42 & $66 \%$ \\
Rata-rata Lemah & $80-89$ & 2 & $5 \%$ & 5 & $8 \%$ \\
Batas Lemah & $70-79$ & 0 & $0 \%$ & 1 & $2 \%$ \\
Lemah mental & $30-63$ & 0 & $0 \%$ & 0 & $0 \%$ \\
Total & & 37 & $100 \%$ & 64 & $100 \%$ \\
\hline
\end{tabular}

Berdasarkan Tabel 3 pada kelompok umur termuda yaitu kelompok umur 15 tahun didapatkan total subyek sebanyak 3 subyek (100\%) yang tersebar pada 2 kategori, yaitu kategori sangat superior dengan nilai IQ $\geq 140$ sebanyak 1 subyek 
(33\%) dan kategori superior dengan nilai IQ 90-109 sebanyak 2 subyek(67\%). Sedangkan pada kelompok umur tertua yaitu kelompok umur 20 tahun didapatkan total subyek sebanyak 2 subyek (100\%) dimana keduanya berada di kategori yang sama yaitu kategori rata-rata. Pada kelompok umur 17 tahun dan 18 tahun mayoritas subyek terbanyak berada di kategori rata-rata yaitu 24 subyek $(65 \%)$ pada kelompok umur 17 tahun dan 25 subyek (54\%) pada kelompok umur 18 tahun. Selanjutnya pada tabel 2.10 terdapat gambaran tingkat IQ berdasarkan ada tidaknya riwayat akselerasi.

Dari Tabel 4 pada subyek yang memiliki riwayat akselerasi mayoritas subyek berada pada kategori rata-rata sampai sangat superior. Untuk subyek terbanyak pada kelompok subyek yang tidak memiliki riwayat akselerasi terdapat pada kategori rata-rata dengan IQ 90-109 yaitu sebanyak 55 subyek (63\%).

Tabel 3. Gambaran Tingkat IQ Berdasarkan Usia

\begin{tabular}{|c|c|c|c|c|c|c|c|c|c|c|c|c|c|}
\hline \multirow{2}{*}{ Kategori } & \multirow{2}{*}{ IQ } & \multicolumn{2}{|c|}{15 Tahun } & \multicolumn{2}{|c|}{16 Tahun } & \multicolumn{2}{|c|}{17 Tahun } & \multicolumn{2}{|c|}{18 Tahun } & \multicolumn{2}{|c|}{19 Tahun } & \multicolumn{2}{|c|}{20 Tahun } \\
\hline & & $\mathrm{N}$ & $\%$ & $\mathrm{~N}$ & $\%$ & $\mathrm{~N}$ & $\%$ & $\mathrm{~N}$ & $\%$ & $\mathrm{~N}$ & $\%$ & $\mathrm{~N}$ & $\%$ \\
\hline Sangat & & & & & & & & & & & & & \\
\hline Supe & $\begin{array}{l}\geq 140 \\
120-\end{array}$ & 1 & $33 \%$ & 0 & $0 \%$ & 0 & $0 \%$ & 0 & $0 \%$ & 0 & $0 \%$ & 0 & $0 \%$ \\
\hline Superior & 139 & 2 & $67 \%$ & 2 & $33 \%$ & 7 & $19 \%$ & 4 & $9 \%$ & 0 & $0 \%$ & 0 & $0 \%$ \\
\hline Rat & 110 & & & & & & & & & & & & \\
\hline Ting & 11 & 0 & $0 \%$ & 2 & $33 \%$ & 6 & & 9 & $20 \%$ & & $0 \%$ & 0 & $0 \%$ \\
\hline Rata-rata & 90-109 & 0 & $0 \%$ & 2 & $33 \%$ & 24 & $65 \%$ & 25 & $54 \%$ & 7 & $100 \%$ & 2 & $100 \%$ \\
\hline Rata-rata & & & & & & & & & & & & & \\
\hline Lemah & $80-89$ & 0 & $0 \%$ & 0 & $0 \%$ & 0 & $0 \%$ & 7 & $15 \%$ & 0 & $0 \%$ & 0 & $0 \%$ \\
\hline Batas & 7 & 0 & $0 \%$ & 0 & $0 \%$ & 0 & $0 \%$ & 1 & $2 \%$ & 0 & $0 \%$ & 0 & $0 \%$ \\
\hline Lemah 1 & $30-63$ & 0 & $0 \%$ & 0 & $0 \%$ & 0 & $0 \%$ & 0 & $0 \%$ & 0 & $0 \%$ & 0 & $0 \%$ \\
\hline Total & & 3 & $100 \%$ & 6 & $100 \%$ & 37 & $100 \%$ & 46 & $100 \%$ & 7 & $100 \%$ & 2 & $100 \%$ \\
\hline
\end{tabular}

Tabel 4. Gambaran Tingkat IQ Berdasarkan Riwayat Akselerasi

\begin{tabular}{lcrrrc}
\hline \multicolumn{1}{c}{ Kategori } & IQ & \multicolumn{2}{c}{ Ada } & \multicolumn{2}{c}{ Tidak } \\
& & $\mathrm{N}$ & $\%$ & $\mathrm{~N}$ & $\%$ \\
\hline Sangat Superior & $\geq 140$ & 1 & $7 \%$ & 0 & $0 \%$ \\
Superior & $120-139$ & 6 & $43 \%$ & 9 & $10 \%$ \\
Rata-rata Tinggi & $110-119$ & 1 & $7 \%$ & 16 & $18 \%$ \\
Rata-rata & $90-109$ & 5 & $36 \%$ & 55 & $63 \%$ \\
Rata-rata Lemah & $80-89$ & 1 & $7 \%$ & 6 & $7 \%$ \\
Batas Lemah & $70-79$ & 0 & $0 \%$ & 1 & $1 \%$ \\
Lemah mental & $30-63$ & 0 & $0 \%$ & 0 & $0 \%$ \\
Total & & 14 & $100 \%$ & 87 & $100 \%$ \\
\hline
\end{tabular}

Tabel 5. Gambaran Tingkat IQ Berdasarkan Jalur Masuk Perguruan Tinggi

\begin{tabular}{lccccccc}
\hline \multicolumn{1}{c}{ Kategori } & IQ & \multicolumn{2}{c}{ SNMPTN } & \multicolumn{2}{c}{ SBMPTN } & \multicolumn{2}{c}{ Tumou Tou } \\
& & $\mathrm{N}$ & $\%$ & $\mathrm{~N}$ & $\%$ & $\mathrm{~N}$ & $\%$ \\
\hline Sangat Superior & $\geq 140$ & 0 & $0 \%$ & 1 & $3 \%$ & 0 & $0 \%$ \\
Superior & $120-139$ & 2 & $5 \%$ & 11 & $35 \%$ & 2 & $7 \%$ \\
Rata-rata Tinggi & $110-119$ & 7 & $18 \%$ & 5 & $16 \%$ & 5 & $17 \%$ \\
Rata-rata & $90-109$ & 28 & $70 \%$ & 12 & $39 \%$ & 20 & $67 \%$ \\
Rata-rata Lemah & $80-89$ & 2 & $5 \%$ & 2 & $6 \%$ & 3 & $10 \%$ \\
Batas Lemah & $70-79$ & 1 & $3 \%$ & 0 & $0 \%$ & 0 & $0 \%$ \\
Lemah mental & $30-63$ & 0 & $0 \%$ & 0 & $0 \%$ & 0 & $0 \%$ \\
Total & & 40 & $100 \%$ & 31 & $100 \%$ & 30 & $100 \%$ \\
\hline
\end{tabular}


Berdasarkan tabel 5 pada kelompok yang masuk melalui jalur Seleksi Nasional Masuk Perguruan Tinggi Negeri (SNMPTN) didapatkan sebanyak 2 subyek (5\%) masuk pada kategori superior, 7 subyek $(18 \%)$ pada kategori rata-rata tinggi, 28 subyek $(70 \%)$ pada kategori ratarata, 2 subyek $(5 \%)$ pada kategori rata-rata lemah, dan 1 subyek (3\%) pada kategori batas lemah. Sedangkan subyek yang masuk melalui jalur Seleksi Bersama Masuk Perguruan Tinggi Negeri (SBMPTN) didapatkan sebanyak 1 subyek (3\%) masuk pada kategori sangat superior, 11 subyek $(35 \%)$ pada kategori superior, 5 subyek $(16 \%)$ pada kategori rata-rata tinggi, 12 subyek (39\%) pada kategori ratarata, dan 2 subyek (6\%) pada kategori ratarata lemah. Dan untuk subyek yang masuk melalui jalur Tumou Tou (T2) didapatkan sebanyak 2 subyek (7\%) masuk pada kategori superior, 5 (17) subyek pada kategori rata-rata tinggi, 20 subyek $(67 \%)$ pada kategori rata-rata, dan 3 subyek (10\%) pada kategori rata-rata lemah.

\section{BAHASAN}

Berdasarkan penelitian mengenai gambaran tingkat inteligensi yang telah dilakukan pada mahasiswa program studi pendidikan dokter fakultas kedokteran Universitas Sam Ratulangi dengan responden sebanyak 101 orang. Dari 101 orang, 37 orang $(37 \%)$ laki-laki dan 64 orang $(63 \%)$ perempuan. Berdasarkan hasil penelitian didapatkan rata-rata nilai IQ yaitu 108,63 yang masuk pada kategori rata-rata. Hal ini berbeda dengan hasil penelitian sebelumnya yang dilakukan pada mahasiswa fakultas kedokteran di beberapa universitas. Penelitian yang kemudian digabungkan oleh Matarazzo dan Goldstein $^{11}$ mendapatkan rata-rata nilai IQ mereka mendekati nilai 125 yang masuk pada kategori Superior. Perbedaan nilai rata-rata yang didapatkan mungkin disebabkan oleh tempat penelitian yang berbeda. Penelitian ini diadakan di Indonesia yaitu negara berkembang sedangkan untuk penelitian Matarazzo dilakukan di Amerika yang merupakan negara maju.

Pada hasil penelitian, total subyek terbanyak berada pada kategori Rata-rata sebanyak 60 subyek. Hal ini sejalan dengan penelitian Yesikar V, Guleri SK, Dixit S, Rokade R, dan Parmar $S^{12}$ yang dilakukan pada mahasiswa kedokteran di India pada 2013 sampai 2014 dimana dari total 300 subyek penelitian didapatkan subyek terbanyak berada pada kategori Rata-rata yaitu sebanyak 150 subyek penelitian.

Kemampuan IQ tertinggi di dapatkan pada 1 subyek (1\%) dengan nilai IQ 151 yang masuk dalam kategori sangat superior. Subyek dengan IQ tertinggi adalah subyek berjenis kelamin perempuan yang terdapat dalam kelompok usia 15 tahun serta memiliki riwayat akselerasi. Karakteristik lainnya yang dimiliki oleh subyek ini adalah jalur masuk perguruan tinggi melalui jalur SBMPTN dan berasal dari suku Minahasa. Individu yang memiliki IQ sangat superior memiliki karakteristik antara lain, memiliki daya abstraksi yang baik, mempunyai banyak ide, sangat kritis, sangat kreatif dan suka menganalisis. ${ }^{13}$ Individu dengan IQ sangat superior cenderung membutuhkan pendidikan yang memungkinkan mereka untuk mengolah dan mengembangkan kemampuan yang dimilikinya. Hal ini dilakukan agar mereka dapat meraih potensi terbaik tanpa menimbulkan masalah. Sutisna ${ }^{14}$ mengemukakan masalah-masalah yang mungkin timbul antara lain: cepat bosan terhadap hal-hal mudah, kurang hubungan antara pribadi yang berkemampuan tidak sama, sehingga sukar menyesuaikan diri dalam tugas kelompok, frustrasi terhadap pertimbangan yang dianggap ganjil oleh orang lain, sehingga muncul penolakan dengan bentuk pemberontakan, tidak menyukai pengulangan konsep yang sudah dipahami, dan kecewa akibat kritikan sendiri dan cara orang lain menempatkan dirinya.

Pada penelitian ini juga didapatkan 1 subyek (1\%) dengan nilai IQ yang rendah yaitu nilai IQ 77 yang masuk dalam kategori batas lemah. Karakteristik subyek ini adalah perempuan, masuk dalam 
kelompok umur 18 tahun, tidak memiliki riwayat akselerasi, masuk melalui jalur SNMPTN, serta berasal dari suku Minahasa. Melihat nilai IQ yang kurang, peneliti melakukan wawancara pada subyek ini. Didapatkan keterangan bahwa pada saat pengerjaan soal subyek tidak fokus dalam mengerjakannya karena kelelahan, dan kondisi ruangan yang panas sehingga membuat subyek tidak nyaman. Ayuningtias ${ }^{15}$ mengemukakan faktor-faktor yang muncul saat tes yang kemudian dapat mempengaruhi hasil tes IQ seseorang. Faktor-faktor tersebut antara lain: kondisi individu saat pelaksanaan tes, daya juang dan motivasi, perubahan karakteristik lingkungan, dan kondisi khusus yang dimiliki individu

Berdasarkan hasil penelitian pada karakteristik jenis kelamin didapatkan baik jenis kelamin laki-laki maupun perempuan, subyek terbanyak berada pada kategori IQ rata-rata yaitu sebanyak 18 subyek $(49 \%)$ laki-laki dan 42 subyek (66\%) perempuan. Pada kategori superior subyek terbanyak berasal dari jenis kelamin laki-laki yaitu sebanyak 10 subyek, dibandingkan dengan perempuan sebanyak 5 subyek. Sedangkan untuk kategori dibawah rata-rata lemah dan batas lemah subyek terbanyak berasal dari jenis kelamin perempuan. Berdasarkan hal ini, dapat disimpulkan IQ laki-laki cenderung lebih tinggi dari IQ perempuan. Hasil seperti ini juga sama dengan hasil penelitian yang dilakukan oleh Uppu et al. 16 mengenai perbedaan IQ berdasarkan gender pada mahasiswa kedokteran di fakultas kedokteran Sri Venkateswara dimana IQ laki-laki lebih tinggi dibandingkan IQ perempuan.

Pada karakteristik ada tidaknya riwayat akselerasi didapatkan 8 subyek (57\%) dari total 14 subyek yang memiliki riwayat akselerasi berada pada kategori rata-rata tinggi sampai sangat superior. Untuk subyek yang tidak memiliki riwayat akselerasi dan masuk pada kategori ratarata tinggi sampai sangat superior adalah sebanyak 25 subyek (29\%) dari total 87 subyek. Hasil diatas menunjukkan bahwa tingkat IQ pada mahasiswa yang memiliki riwayat akselerasi lebih tinggi dibandingkan mahasiswa yang tidak memiliki riwayat akselerasi. Hal ini sama dengan hasil penelitian Wardhani et al. ${ }^{17}$ yang dilakukan pada mahasiswa Fakultas Kedokteran Universitas Indonesia, bahwa mahasiswa yang sebelumnya pernah mengikuti program akselerasi cenderung memiliki kecerdasan yang tergolong baik sekali.

Hasil penelitian yang diperoleh memperlihatkan bahwa kemampuan IQ dari mahasiswa yang menjadi subyek penelitian di program studi pendidikan dokter fakultas kedokteran Universitas Sam Ratulangi bervariasi. Keberagaman yang timbul dapat disebabkan oleh faktor-faktor yang dapat mempengaruhi IQ seseorang. Faktor-faktor tersebut diantaranya dikemukakan oleh Khairani $^{3}$ yaitu pembawaan, kematangan, pembentukan, minat dan pembawaan yang khas, dan kebebasan. Selain itu $\operatorname{Arsyad}^{18}$ juga dalam penelitiannya mengemukakan bahwa faktor genetik juga dapat mempengaruhi IQ seseorang, dengan nilai korelasi cukup tinggi yaitu 0,32 .

\section{SIMPULAN}

Berdasarkan penelitian yang dilakukan pada 101 subyek didapatkan hasil tingkat kemampuan IQ dengan kategori sangat superior $(1 \%)$, kategori superior $(15 \%)$, kategori rata-rata tinggi (28\%), kategori rata-rata $(49 \%)$, kategori di bawah rata-rata (7\%), dan sisanya (1\%) pada kategori batas lemah.

Nilai IQ tertinggi yaitu 151 yang masuk di kategori sangat superior didapatkan pada 1 subyek dengan karakteristik perempuan, kelompok usia 15 tahun, suku Minahasa, ada riwayat akselerasi dan masuk perguruan tinggi melalui jalur SBMPTN. Untuk nilai IQ terendah didapatkan pada 1 subyek dengan karakteristik perempuan, kelompok usia 18 tahun, suku Minahasa, tidak ada riwayat akselerasi dan masuk perguruan tinggi melalui jalur SNMPTN.

\section{SARAN}

1. Dalam penelitian ini didapatkan hasil tes 
IQ mahasiswa Program Studi Pendidikan Dokter Fakultas Kedokteran Universitas Sam Ratulangi Manado angkatan 2016, diharapkan agar dapat digunakan oleh fakultas dalam hal evaluasi kecerdasan intelektual mahasiswa. Selain itu peneliti juga menyarankan agar tes IQ bagi mahasiswa tahun pertama dapat dilakukan secara berkelanjutan. Agar fakultas dapat mengetahui bagaimana tingkat inteligensi mahasiswa yang diterima setiap tahunnya yang kemudian dapat menjadi bahan pertimbangan bagi fakultas.

2. Keterbatasan dalam penelitian ini adalah waktu dan keadaan saat penelitian yang kurang mendukung untuk dilaksanakannya tes, sehingga hasil yang didapatkan kurang maksimal. Untuk itu peneliti menyarankan bagi peneliti yang akan melaksanakan penelitian lanjut agar dapat lebih memperhatikan hal-hal diatas, serta dapat lebih memperluas variabel penelitian bahkan dapat meneliti hubungan antar variabel penelitian.

3. Untuk bahan informasi bagi dosen mengenai mahasiswa didikannya, bagaimana kreatifitas dosen dalam pengelolaan kelas dengan ragam IQ yang dimiliki mahasiswa program studi pendidikan dokter fakultas kedokteran Universitas Sam Ratulangi angkatan 2016.

4. Untuk mahasiswa angkatan 2016 untuk menjadi bahan evaluasi diri agar lebih giat lagi dalam belajar dan lebih mengoptimalkan waktu yang ada untuk mengembangkan kemampuan masingmasing individu.

\section{DAFTAR PUSTAKA}

1. Supardi US. Arah pendidikan di Indonesia dalam tataran kebijakan dan implementasi. Jurnal Formatif. 2012;2(2):111-21

2. UU no.12 tahun 2012 tentang pendidikan tinggi (eBook). [Diakses 22 Agu 2016]. Tersedia di: https://portal.mahkamahkonstitusi.go.
id/eLaw/mg58ufsc89hrsg/1f32ffaa83 555e001038d1e0cda7b281849acef2d. pdf.

3. Khairani H. Makmun. Psikologi belajar. Cetakan II. Yogyakarta: Aswaja Pressindo; 2014

4. Saryono D. Intelegensi dan kepribadian. 2008 [diakses 16 Agu 2016]. Tersedia di: http://waraskamdi.com.

5. Solso RL, Maclin OH, Maclin MK. Psikologi kognitif. Terjemahan. Edisi Kedelapan. Jakarta: Erlangga; 2008

6. Arisandy D. Psikodiagnostik III-Inteligensi. Palembang: Bina Darma; 2006

7. Kiss M, Kotsis Á, Kun AI. The relationship between intelligence, emotional intelligence, personality styles and academic success. BEA 2014;6(2)

8. Reteng $\mathbf{P}$, Wungouw HIS, Polii H. Nilai Intelligence Quotient (IQ) dan nilai ujian modul mahasiswa angkatan 2013 fakultas kedokteran Universitas Sam Ratulangi. Ejournal UNSRAT [Internet]. 2014 [diakses 17 Agt 2016]. Tersedia di: http://ejournal.unsrat.ac.id/index.php/ ebiomedik/article/view/3644.

9. Amthauer R. I-S-T 70: Intelligenz Struktur Test. Handanweisung fur die Durchfuhrung und Auswertung.4. Auflage. Gottingen: Hogrefe. 1973

10.Anastasi A, Urbina S. Tes Psikologi. Terjemahan. Edisi Ketujuh. Jakarta: PT Indeks; 2006

11.Matarazzo JD, Goldstein SG. The intellectual caliber of medical students. Journal of Medical Education. 1972;47:102-11

12. Yesikar V, Guleri SK, Dixit S, Rokade R, Parmar S. Intelligence quotient analysis and its association with academic performance of medical student. Int. J Community Med Public Health. 2015;2(3):275-81

13.Sutratinah $\mathbf{T}$. Anak supernormal dan program pendidikannya. Jakarta: Bina Aksara. 1984

14.Sutisna N. Anak Berbakat. [Internet]. [Diakses 14 Nov 2016]. Tersedia di: http://file.upi.edu/Direktori/FIP/JUR. _PEND._LUAR._BIASA/195701311 986031-

NIA_SUTISNA/BAB_11.pdf\&ved=0 ahUKEwi2cL 
15.Ayuningtias M. Apa yang harus diketahui tentang tes IQ (tes intelegensi). [Internet]. 2014 [Diakses 16 Nov 2016]. Tersedia di: https://pantirehabilitasi.com/2014/04/ 16/apa-yang-harus-diketahui-tentangtes-iq-tes-intelegensi/

16.Uppu B, Devi V, Anitha N, Radhika RKC. Gender performance on intelligence quotient test among medical students in a government medical college. IOSR-JDMS. 2015;14(10):17-21
17.Wardhani SLS, et al. Kinerja akseleran dalam rotasi klinik: suatu kajian terhadap pencapaian kompetensi klinik mahasiswa kedokteran. Jurnal Psikologi. 2014;41(1):34-46

18.Arsyad L. Pengaruh faktor genetik dan intelegensi terhadap keberhasilan belajar anak. Ejournal IAINGorontalo. [Internet]. 2014 [Diakses 12 Nov 2016]. Tersedia di: http://www.journal.iaingorontalo.ac.i d/index.php/tjmpi/article/view/248\&v ed. 